\title{
Developing Empirical Decision Points to Improve the Timing of Adaptive Digital Health Physical Activity Interventions in Youth: Survival Analysis
}

\author{
Corresponding Author: \\ Christopher C Cushing, $\mathrm{PhD}$ \\ Schiefelbusch Life Span Institute \\ University of Kansas \\ 1000 Sunnyside Avenue \\ Lawrence, KS \\ United States \\ Phone: 17858640713 \\ Email: christopher.cushing@ku.edu
}

Adrian Ortega ${ }^{1}, \mathrm{MA}$; Christopher C Cushing ${ }^{1,2}, \mathrm{PhD}$

${ }^{1}$ Clinical Child Psychology Program, University of Kansas, Lawrence, KS, United States

${ }^{2}$ Schiefelbusch Life Span Institute, University of Kansas, Lawrence, KS, United States

\section{Abstract}

Background: Current digital health interventions primarily use interventionist-defined rules to guide the timing of intervention delivery. As new temporally dense data sets become available, it is possible to make decisions about the intervention timing empirically.

Objective: This study aimed to explore the timing of physical activity among youth to inform decision points (eg, timing of support) for future digital physical activity interventions.

Methods: This study comprised 113 adolescents aged between 13 and 18 years (mean age 14.64, SD 1.48 years) who wore an accelerometer for 20 days. Multilevel survival analyses were used to estimate the most likely time of day (via odds ratios and hazard probabilities) when adolescents accumulated their average physical activity. The interacting effects of physical activity timing and moderating variables were calculated by entering predictors, such as gender, sports participation, and school day, into the model as main effects and tested for interactions with the time of day to determine conditional main effects of these predictors.

Results: On average, the likelihood that a participant would accumulate a typical amount of moderate-to-vigorous physical activity increased and peaked between 6 PM and 8 PM before decreasing sharply after 9 PM. Hazard and survival probabilities suggest that optimal decision points for digital physical activity programs could occur between 5 PM and 8 PM.

Conclusions: Overall, the findings of this study support the idea that the timing of physical activity can be empirically identified and that these markers may be useful as intervention triggers.

(JMIR Mhealth Uhealth 2020;8(6):e17450) doi: $\underline{10.2196 / 17450}$

\section{KEYWORDS}

telemedicine; exercise; physical activity; adolescent

\section{Introduction}

\section{Background}

Less than $25 \%$ of the youth attain the recommended amounts (60 min per day) of moderate-to-vigorous physical activity (MVPA) [1]. Despite the importance of physical activity for health [2-4], it is well documented that rates of daily MVPA decrease from childhood to adolescence about 40 min each year between ages 9 and 15 years [5]. Accordingly, adolescence is a stage when the youth are likely to exhibit declines in physical activity [6], and therefore, empirical research investigating the patterns of physical activity in adolescence may have value for future interventions to forestall this decline.

The daily activity of youths is in four levels: sleep, sedentary activity, light activity, and MVPA [7,8]. The time spent in each of these levels is strongly linked, such that reducing or increasing the time spent in one of these levels is inversely related to how much time is spent in other levels $[9,10]$. As the 
youth choose to pursue sedentary activities (eg, watching television), the time and opportunity available for exercise decrease. In other words, there is a finite number of minutes in the day, and every passing minute of physical inactivity results in a loss of opportunity for physical activity.

There is growing interest among behavioral scientists to translate efficacious behavioral interventions for improving physical activity into digital modalities [11,12]. Although mobile health interventions for improving health behavior are efficacious, these interventions primarily use technologies to send reminder messages to users [13]. Moreover, high nonusage attrition and declined user engagement throughout the intervention are concerns in the digital health literature [14,15]. Greater intervention precision, such as timely support, may improve digital intervention effectiveness and engagement [16].

Just-in-time adaptive interventions (JITAIs) capitalize on advanced digital technologies and computer automation to tailor digital interventions to the user's needs and deliver these interventions at opportune moments [16]. A critical component of JITAIs is the decision point or timing of support [16]. JITAIs seek to intervene at critical windows of opportunity for each user to maximize effectiveness and engagement while also minimizing waste or participant burden; however, consistent methods of developing decision points have not been established [16]. In the absence of a clear theory to guide when JITAIs should intervene, it is valuable to empirically identify critical windows of opportunity that can be adjusted based on users' needs rather than at moments made a priori by investigators as intervention decision points [17]. However, very few digital physical activity interventions have adjusted the timing of intervention delivery based on observed patterns of physical activity [17]. A recent meta-analysis [18] revealed that most physical activity JITAIs modified decision points based on rational decisions, such as interventionist-defined [19-21] or user-defined times [22]. Physical activity JITAIs dynamically tailored their interventions at the individual level based on context-aware sensing and machine learning algorithms [23,24], how and the extent to which the decision points were modified beyond content adaptations, and its unique effect on changes in physical activity remains unclear. In other words, despite these studies, a research gap still remains regarding when adolescents allocate time to physical activity and how we can best leverage these times to improve exercise attainment digitally.

An investigation of the temporal windows of users' previous exercise patterns can help pinpoint subsequent decision points for intervention. It may prove beneficial to investigate the timing of activity in the youth to identify critical windows of opportunity for when users allocate time to engage in physical activity. Thus, digital interventions can optimize intervention delivery and maximize engagement in physical activity when it is likely to occur for users. By delivering support at the empirically observed moments and at random, interventionist-defined users, or user-selected decision points, may be more likely to exhibit health-promoting behaviors, such as physical activity.

\section{Study Aims and Hypotheses}

The primary objective of this study (aim 1) was to explore the time of day when an adolescent accumulated their average physical activity. This aim explored the most likely hour by which an adolescent would have accumulated their average physical activity, given that it had not occurred already. As adolescents are unlikely to meet the recommended $60 \mathrm{~min}$ of MVPA each day, this study examined the likelihood that each participant met their average unique MVPA. Aim 1 was exploratory, with no a priori hypothesis postulated.

The secondary objective (aim 2) was to explore day-level and individual-level factors that moderate the likelihood of accumulating physical activity at the time of day found in the primary aim of this study. For this study, the determinants selected for moderation analyses included empirically derived variables previously shown to be correlated with physical activity, such as gender, BMI, sports participation, and school day [25-30]. The primary focus of aim 2 was to determine the magnitude of group differences in the odds of meeting their average MVPA. Gender and BMI are related to exercise attainment and could influence when adolescents meet their average MVPA. For example, because males and individuals with lower BMI engage in more physical activity, they may be more likely to meet their average MVPA compared with females or individuals with a higher BMI. In addition, participation in organized sports or days in which a person attends school might also permit or constrain opportunities to exercise, thereby affecting timing as well. It is hypothesized that youths who participate in sports will obtain higher odds ratios (ORs) of meeting their average MVPA compared with youths who do not participate in sports and that youths will obtain higher ORs of meeting their average MVPA on days in which they attended school than on days in which they did not.

Finally, the third aim (aim 3) was to generate decision points to improve the timing of digital physical activity interventions, given the results from aims 1 and 2. Sets of decision points were inferred from hazard and survival probabilities (see Statistical Analyses section). Decision points were generated for moderators only if the following two conditions were satisfied: (1) if a moderator was found to be significantly different between groups of individuals and (2) if the differences between these groups were as hypothesized in aim 2 . These criteria were set forth so that decision points would only be made for subgroups in which there were meaningful differences in the timing of physical activity and to eliminate ineffectual moderators.

\section{Methods}

\section{Recruitment}

Participants were recruited as part of a study examining the associations between various psychological constructs and physical activity behaviors. Participants learned about the study through flyers posted around the local community. Interested participants were instructed to contact study personnel via phone calls to screen for eligibility. Participants enrolled in the study were aged between 13 and 18 years and lived at home with their caregiver or caregivers. Participants were excluded if they had 
any significant physical maladies that would limit physical activity, visual impairments, or an inability to read at their corresponding grade level. These exclusion criteria were in place to ensure a valid assessment of physical activity. A total of 121 adolescents were recruited to participate.

\section{Procedures}

At the baseline visit, participants reviewed the study information and an institutional review board-approved informed consent form with the research staff and gave consent to participate. For participants aged $<18$ years, their parents provided informed consent, and adolescents provided informed assent. The participants then completed a demographics questionnaire, a planned activity calendar, and were oriented to the accelerometer. Participants were instructed to wear the accelerometer on their nondominant wrist for the entire 20-day study period [31]. Finally, the research staff measured each participant's height and weight. Adolescents then wore the accelerometer for 20 days. At the end of the 20 days, participants returned for a laboratory exit visit to return the accelerometers. When all procedures were completed, participants received up to US \$40 financial compensation for both laboratory visits and completing the surveys (US \$25) and for wearing the accelerometer for at least 18 of the required 20 days (US \$15). Data were collected year-round, beginning in June 2015 and ending in December 2017, across multiple seasons, and when the youth were in and out of school (ie, weekends and weekdays as well as during summer/winter breaks).

\section{Ethics Approval and Consent to Participate}

In accordance with the revised Common Rule, this study was approved by the sponsoring institution's human subjects' protection committee, and all participants provided informed consent and assent.

\section{Sample Characteristics}

Participants were excluded from the current analyses if they had less than 4 days of valid accelerometer wear (eg, $\geq 8$ hours of accelerometer wear time per day, $n=8$ ). Participants in the current analyses $(\mathrm{N}=113)$ were aged between 13 and 18 years (mean 14.64, SD 1.48 years). The sample was $37.2 \%$ men $(32 / 113)$ and $62.8 \%$ women (71/113). In terms of caregiver demographics, $66.4 \%$ (75/113) of parents were married; $22.1 \%$ (25/113) were divorced, separated, or widowed; and $11.5 \%$ (13/113) were never married. Moreover, 61.1\% (69/113) of mothers and $63.7 \%(72 / 113)$ of fathers attained a college education or higher. The majority of the sample $(61.1 \%, 69 / 113)$ reported an approximate family income greater than US $\$ 60,000$. The sample was $78.8 \%$ (89/113) Caucasian, $8.0 \%$ (9/113) Latino/Latina, 4.4\% (5/113) African American, 1.8\% (2/113) multiracial, $0.9 \%$ (1/113) Native American, and 2.7\% (3/113) other.

\section{Measures and Measurement}

\section{Demographics}

Adolescents self-reported basic demographic information, including date of birth, age, sex, race, level(s) of parental education, and approximate family income.

\section{Physical Activity}

The ActiGraph wGT3X-BT accelerometer (ActiGraph LLC) objectively measured participants' MVPA throughout the duration of the 20-day study period. The accelerometers were programmed to sample movements at a rate of $30 \mathrm{~Hz}$ on three different axes, as in previous studies [32] measuring physical activity in the youth. Irrelevant activity periods such as sleep periods and nonwear periods were identified using the Sadeh algorithm and the Troiano algorithm, respectively, and thus removed from the daily activity counts $[33,34]$. Only days when participants wore the accelerometer for 8 hours or more were included in this study. As in previous studies using wrist-worn accelerometers in youths, the Chandler algorithm was used to identify total minutes of MVPA per day [32,35]. Given previous research demonstrating participant reactivity to accelerometer measurement during the first days of the study, research personnel removed the first 3 days of accelerometer activity data for each participant because of potential activity-based reactivity [36]. After removing these days, the mean of each participant's unique MVPA was created by calculating the mean of their daily MVPA attainment.

\section{BMI}

BMI was calculated using the Center for Disease Control and Prevention (CDC) growth charts [37]. Participants' height in centimeters, weight in kilograms, sex, and age in months at the time of study initiation were used to compute BMI. BMI was calculated using the SAS program for the CDC growth charts found on the CDC website [38].

\section{Sports Participation}

During the baseline session, participants were asked if they had any planned physical activity, such as involvement in organized sports, for the next 20 days. Similar to previous studies, participants were dichotomously categorized into 2 groups: involved in organized sports and uninvolved in organized sports based on their self-reported activity involvement [25,39-41].

\section{School Day}

Research personnel classified daily activity patterns into categorical variables: school day and nonschool day to better capture the variability among physical activity patterns for days when youths are in school or not. As in previous retrospective studies investigating the magnitude of physical activity and sedentary time differences when youths are in and out of school, research personnel used the school calendar to classify school days vs nonschool days [42].

\section{Statistical Analyses}

To address the aims of this study, multilevel survival analyses using logistic regression were conducted to examine the hour of day when adolescents accumulated their average physical activity. Predictors were entered into the model as main effects and subsequently tested as interactions with the time of day to determine the conditional main effects of study moderators on the time of day when adolescents accumulated their average physical activity. For the purposes of this project, the time of day was analyzed as a discrete time variable. Using a special case of logistic regression, a hazard function, or the probability 
of the event occurring before the time (hour of day, in this case), conditional on no earlier occurrence, was estimated [43].

To estimate hazard functions, multiple smoothing procedures using polynomial functions of time were tested [43]. For each survival analysis, polynomials of time were entered into the model as linear, quadratic, and cubic predictors of the event. Each survival analysis was estimated using maximum likelihood estimation based on Laplace approximation in SAS PROC GLIMMIX. Nested model comparisons using the chi-square difference of the estimated $-2 \times \log$ likelihood ratio tests for each of these models were evaluated to determine the best fitting model for the polynomial effect of time. Predictors as well as interactions between predictors and time of day were then entered into the hazard model. Each of these hazard models was estimated separately. In the event of a significant interaction of a predictor and time of day, the effect of these interactions was determined by comparing the OR of the estimates by summing all parameter estimates multiplied by their respective variables and then using the inverse link function (ie, $e^{\log (\mathrm{y}=1)}$ ) to translate estimated logits into ORs. To compare the estimates, ORs were calculated by inserting meaningful values into the explanatory predictors in the regression equations. To address aims 1 and 2 OR estimates were used to determine the most likely hour of average MVPA accumulation and group differences in the timing of MVPA obtainment using $8 \mathrm{AM}$ as the reference hour. To investigate whether there were significant differences in the magnitude of the ORs for the time of average MVPA accumulation between groups at $P$ values $<.05$ level of significance, the 95\% CIs around the estimated ORs were compared. OR estimates that did not overlap based on their given $95 \%$ confidence bands were considered statistically significant at the $P$ value <.05 level [44]. For each moderator, statistical differences between groups at every hour of the day were examined.
If the ORs were statistically significant for a window of time in the hypothesized direction, decision points using hazard and survival probabilities were developed, as stated in aim 3 . The hazard and survival probabilities were created by translating the estimated logits into probabilities. Survival probabilities represent the cumulative risk that an individual would not have met the event at a certain time. To estimate the survival probability at each hour, we multiplied the complement of the hazard probabilities (ie, $1 \times$ probability) for that hour and all previous hours [45].

\section{Results}

\section{Preliminary Analyses}

On average, participants accumulated $30.91 \mathrm{~min}$ (SD 30.94; range 0-98.16) of MVPA per day and, therefore, did not meet the recommended guidelines. Participants wore the accelerometer for an average of 17.60 (SD 4.5; range 1-25) valid wear days.

\section{Aim 1}

After inserting sequential polynomials of time, nested model comparisons indicated that a cubic function of time was the best fitting model. On average, the likelihood that a participant would accumulate their own average MVPA increased and peaked between 6 PM and 8 PM (OR 13.19-13.02) before decreasing sharply after 9 PM (Table 1 and Figure 1). No participants met their average MVPA before 8 AM or after 11 PM. For this reason, tables and figures displaying results for aims 1 to 3 reflect the ORs, hazard probabilities, and survival probabilities that an individual met their average MVPA by that hour, conditional on no earlier occurrence, beginning between the hours before $8 \mathrm{AM}$ and terminating before $11 \mathrm{PM}$. 
Table 1. Odds ratio estimates of obtaining average moderate-to-vigorous physical activity before hour of day.

\begin{tabular}{lll}
\hline Hour & Frequency $^{\mathrm{a}}$ & \multicolumn{1}{l}{ Odds ratio estimates $(95 \% \text { CI })^{\mathrm{N}}$} \\
\hline Before 8 AM (reference) & 0 & N/A $^{\mathrm{b}}$ \\
Before 9 AM & 5 & $1.24(1.31-1.36)$ \\
Before 10 AM & 21 & $1.60(1.34-1.91)$ \\
Before 11 AM & 18 & $2.13(1.67-2.72)$ \\
Before noon & 24 & $2.87(2.12-3.7)$ \\
Before 1 PM & 22 & $3.90(2.73-5.56)$ \\
Before 2 PM & 24 & $5.24(3.53-7.77)$ \\
Before 3 PM & 50 & $6.90(4.51-10.55)$ \\
Before 4 PM & 55 & $8.79(5.63-13.72)$ \\
Before 5 PM & 85 & $10.70(6.78-16.89)$ \\
Before 6 PM & 89 & $12.30(7.77-19.45)$ \\
Before 7 PM & 82 & $13.19(8.38-20.73)$ \\
Before 8 PM & 91 & $13.02(8.38-20.22)$ \\
Before 9 PM & 79 & $11.70(7.66-17.84)$ \\
Before 10 PM & 43 & $9.45(6.3-14.12)$ \\
Before 11 PM & 32 & $6.77(4.6-9.94)$ \\
\hline
\end{tabular}

${ }^{\mathrm{a}}$ Frequency represents the number of instances in which users met their average moderate-to-vigorous physical activity before hour of day.

${ }^{\mathrm{b}}$ N/A: not applicable.

Figure 1. Odds ratios of obtaining average moderate-to-vigorous physical activity before each hour of day.

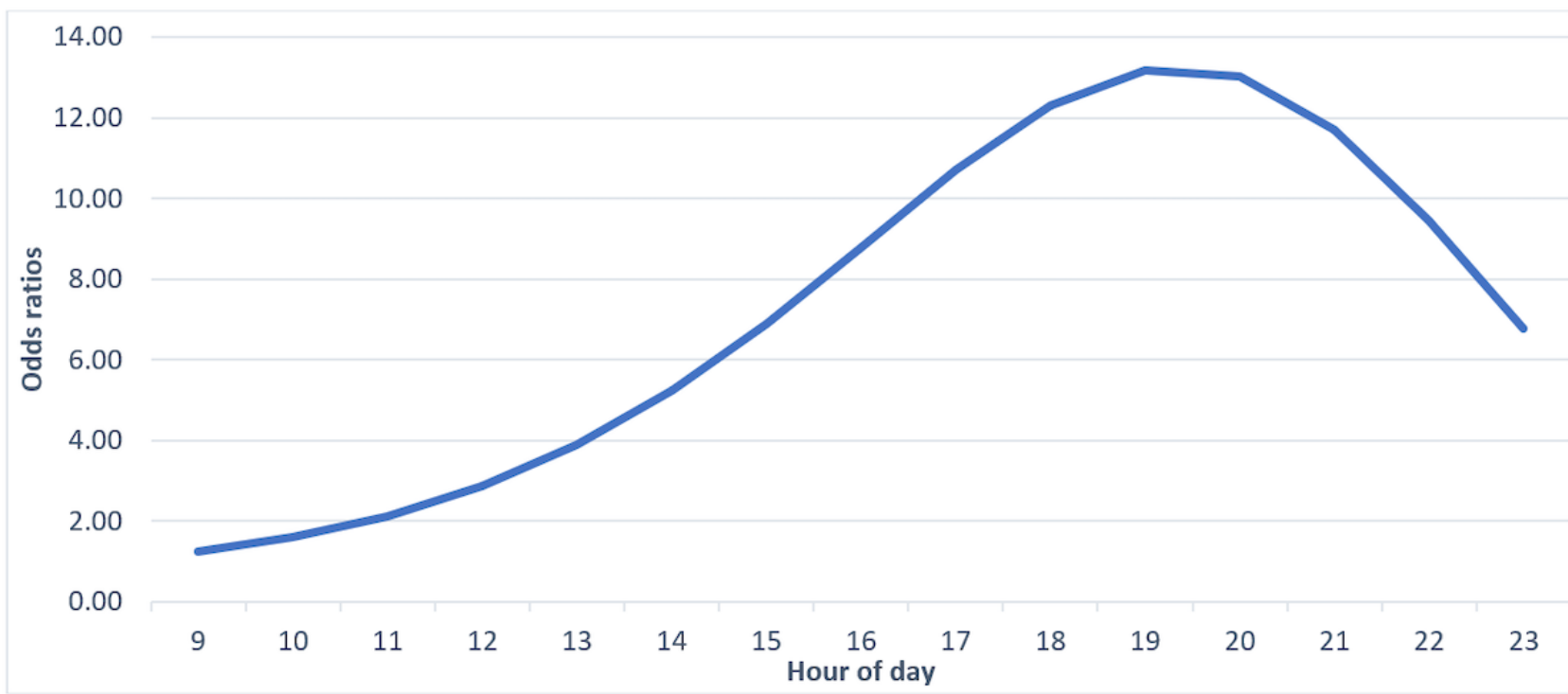

\section{Aim 2}

Compared with $8 \mathrm{AM}$, male adolescents had significantly higher odds of obtaining their average MVPA only between the 8 AM and noon window compared with female adolescents (Table 2 and Figure 2).

BMI did not significantly moderate the relationship between time of day and MVPA attainment (Table 3 and Figure 3).
In addition, adolescents involved in organized sports had significantly lower odds of attaining their average MVPA between $8 \mathrm{AM}$ and $10 \mathrm{AM}$ (Table 4 and Figure 4).

Adolescents had significantly higher odds between the 8 AM and noon window, compared with $8 \mathrm{AM}$, of meeting their average MVPA on nonschool days compared with school days (Table 5 and Figure 5). 
Table 2. Moderating effect of sex on odds ratio estimates of time of average moderate-to-vigorous physical activity accumulation.

\begin{tabular}{|c|c|c|}
\hline \multirow[t]{2}{*}{ Hour } & \multicolumn{2}{|c|}{ Odds ratio estimates $(95 \% \mathrm{CI})$} \\
\hline & Males $^{\mathrm{a}}(\mathrm{n}=42)$ & Females $^{\mathrm{b}}(\mathrm{n}=71)$ \\
\hline Before 8 AM (reference) & $\mathrm{N} / \mathrm{A}^{\mathrm{c}}$ & N/A \\
\hline Before 9 AM & $1.52(1.29-1.79)^{\mathrm{d}}$ & $1.12(1-1.25)$ \\
\hline Before $10 \mathrm{AM}$ & $2.30(1.8-3.34)^{\mathrm{d}}$ & $1.33(1.08-1.64)$ \\
\hline Before $11 \mathrm{AM}$ & $3.43(2.42-5.78)^{\mathrm{d}}$ & $1.66(1.24-2.23)$ \\
\hline Before noon & $5.02(3.21-9.54)^{\mathrm{d}}$ & $2.16(1.49-3.11)$ \\
\hline Before 1 PM & $7.15(4.2-14.95)$ & $2.86(1.85-4.38)$ \\
\hline Before $2 \mathrm{PM}$ & $9.83(4.87-16.66)$ & $3.81(2.35-6.11)$ \\
\hline Before 3 PM & $12.94(6.07-27.23)$ & $5.04(3-8.36)$ \\
\hline Before 4 PM & $16.20(7.31-35.35)$ & $6.52(3.76-11.04)$ \\
\hline Before 5 PM & $19.12(8.43-42.52)$ & $8.11(4.61-13.88)$ \\
\hline Before 6 PM & $21.13(9.26-47.12)$ & $9.58(5.41-16.38)$ \\
\hline Before 7 PM & $21.69(9.57-47.79)$ & $10.58(6-19.91)$ \\
\hline Before 8 PM & $20.52(9.24-44.12)$ & $10.77(6.18-17)$ \\
\hline Before 9 PM & $17.76(8.23-36.87)$ & $9.96(5.81-16.15)$ \\
\hline Before $10 \mathrm{PM}$ & $13.96(6.7-27.81)$ & $8.24(4.89-13.01)$ \\
\hline Before 11 PM & $9.88(4.9-18.91)$ & $6.02(3.62-9.27)$ \\
\hline
\end{tabular}

${ }^{a}$ Average moderate-to-vigorous physical activity for men $=31.48 \mathrm{~min}$.

${ }^{\mathrm{b}}$ Average moderate-to-vigorous physical activity for women=30.66 min.

${ }^{\mathrm{c}} \mathrm{N} / \mathrm{A}$ : not applicable.

${ }^{\mathrm{d}}$ Significant differences in odds ratios between groups based on nonoverlapping CIs.

Figure 2. Sex differences in odds ratios of obtaining average moderate-to-vigorous physical activity before each hour of day.

25

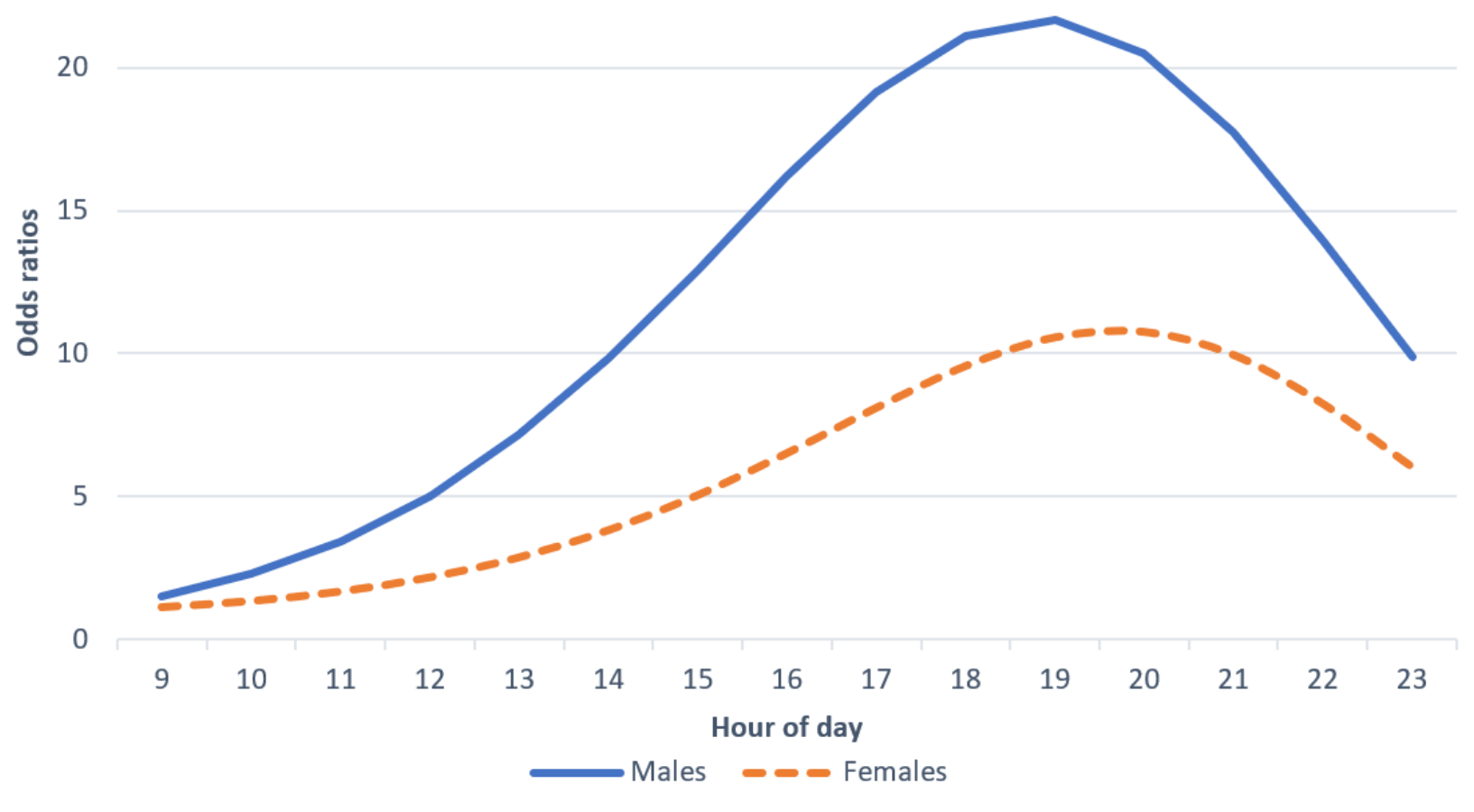


Table 3. Moderating effect of BMI on odds ratio estimates of time of average moderate-to-vigorous physical activity accumulation.

\begin{tabular}{llll}
\hline Hour & \multicolumn{2}{l}{ Odds ratio estimates $(95 \% \mathrm{CI})$} & \\
& \multicolumn{1}{l}{ Normal weight status $^{\mathrm{a}}(\mathrm{n}=81)$} & Overweight status $^{\mathrm{b}}(\mathrm{n}=13)$ & Obese status $^{\mathrm{c}}(\mathrm{n}=19)$ \\
\hline Before 8 AM (reference) & $\mathrm{N}^{\mathrm{d}}$ & $\mathrm{N} / \mathrm{A}$ & N/A \\
Before 9 AM & $1.28(1.16-1.39)$ & $1.25(1.14-1.36)$ & $1.24(1.24-1.36)$ \\
Before 10 AM & $1.68(1.4-1.97)$ & $1.61(1.36-1.9)$ & $1.59(1.34-1.89)$ \\
Before 11 AM & $2.26(1.76-2.83)$ & $2.14(1.68-2.7)$ & $2.10(1.64-2.68)$ \\
Before noon & $3.07(2.25-4.07)$ & $2.86(2.12-3.83)$ & $2.8(2.06-3.8)$ \\
Before 1 PM & $4.16(2.91-5.81)$ & $3.83(2.7-5.4)$ & $3.74(2.61-5.33)$ \\
Before 2 PM & $5.57(3.76-8.12)$ & $5.06(3.42-7.44)$ & $4.93(3.3-7.35)$ \\
Before 3 PM & $7.29(4.79-10.99)$ & $6.54(4.29-9.92)$ & $6.34(4.09-9.8)$ \\
Before 4 PM & $9.22(5.95-14.24)$ & $8.15(5.23-12.67)$ & $7.87(4.95-12.5)$ \\
Before 5 PM & $11.14(7.17-17.48)$ & $9.68(6.13-15.29)$ & $9.30(5.73-15.09)$ \\
Before 6 PM & $12.73(8.11-20.11)$ & $10.83(6.82-17.27)$ & $10.35(6.3-17.03)$ \\
Before 7 PM & $13.58(8.7-21.44)$ & $11.29(7.11-18.04)$ & $10.71(6.48-17.79)$ \\
Before 8 PM & $13.40(8.66-20.99)$ & $10.82(6.85-17.25)$ & $10.18(6.14-17.01)$ \\
Before 9 PM & $12.09(7.91-18.67)$ & $9.43(6.01-14.95)$ & $8.79(5.29-14.74)$ \\
Before 10 PM & $9.86(6.53-14.96)$ & $7.39(4.74-11.64)$ & $6.80(4.09-11.47)$ \\
Before 11 PM & $7.19(4.79-10.72)$ & $5.13(3.31-8.07)$ & $4.66(2.79-7.94)$ \\
\hline
\end{tabular}

${ }^{\mathrm{a}}$ Mean moderate-to-vigorous physical activity (MVPA) for normal weight status=31.23 min .

${ }^{\mathrm{a}}$ Mean MVPA for overweight status $=27.33 \mathrm{~min}$.

${ }^{c}$ Mean MVPA for obese status $=32.32$.

${ }^{\mathrm{d}} \mathrm{N} / \mathrm{A}$ : not applicable. 
Figure 3. BMI differences in odds ratios of obtaining average moderate-to-vigorous physical activity before each hour of day.

16.00

14.00

12.00

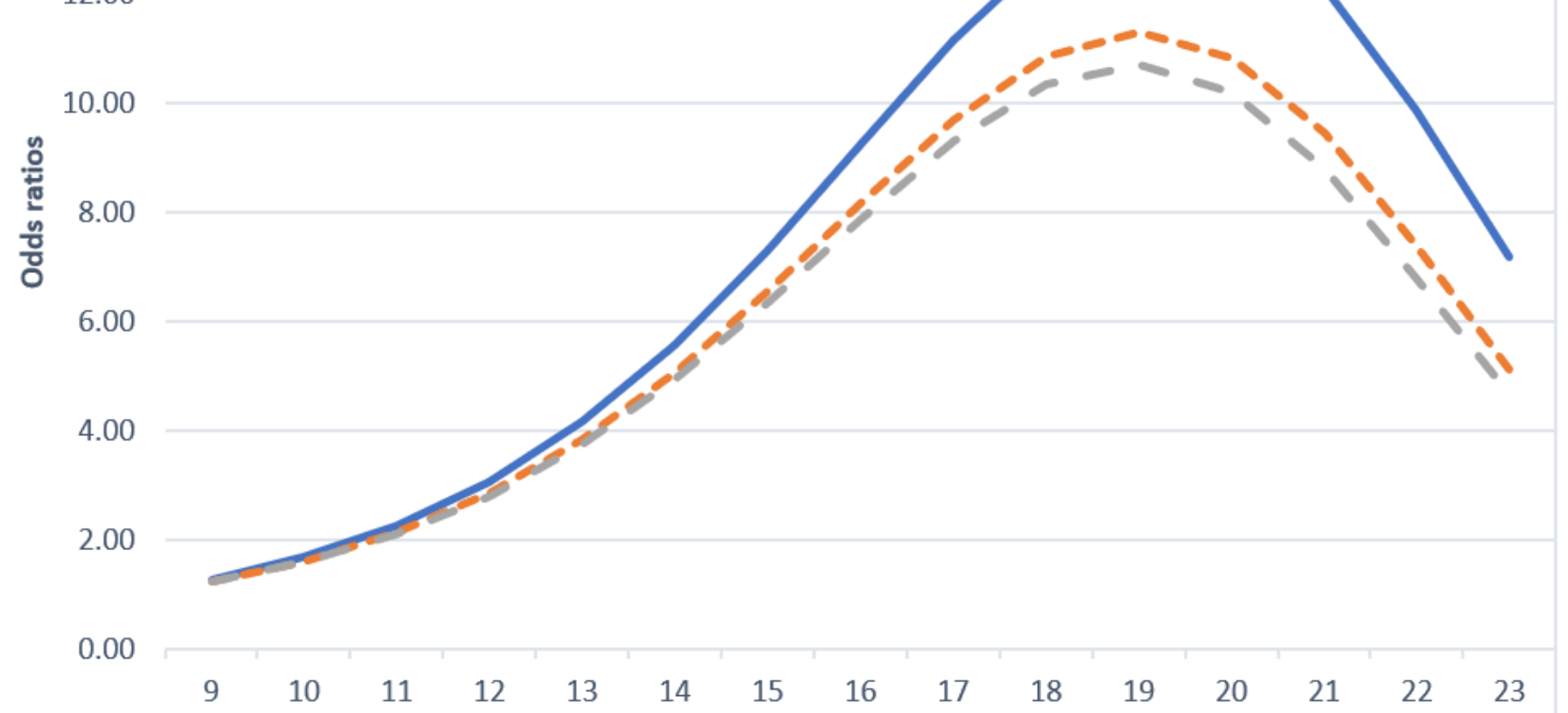

Hour of day

Normal Weight -- Overweight - Obese 
Table 4. Moderating effect of involvement in organized sports (sports participation) on odds ratio estimates of time of average moderate-to-vigorous physical activity accumulation.

\begin{tabular}{|c|c|c|}
\hline \multirow[t]{2}{*}{ Hour } & \multicolumn{2}{|l|}{ Odds ratio estimates $(95 \% \mathrm{CI})$} \\
\hline & No sports participation $^{\mathrm{a}}(\mathrm{n}=68)$ & Sports participation $^{\mathrm{b}}(\mathrm{n}=45)$ \\
\hline Before 8 AM (reference) & $\mathrm{N} / \mathrm{A}^{\mathrm{c}}$ & N/A \\
\hline Before 9 AM & $1.41(1.26-1.58)^{\mathrm{d}}$ & $0.95(0.81-1.12)$ \\
\hline Before $10 \mathrm{AM}$ & $1.95(1.62-2.48)^{\mathrm{d}}$ & $1.05(0.78-1.43)$ \\
\hline Before $11 \mathrm{AM}$ & $2.65(1.96-3.57)$ & $1.32(0.86-2.02)$ \\
\hline Before noon & $3.51(2.42-5.1)$ & $1.83(1.16-3.41)$ \\
\hline Before 1 PM & $4.54(2.94-7)$ & $2.68(1.44-4.96)$ \\
\hline Before 2 PM & $5.71(3.53-9.25)$ & $4.06(2.2-8.9)$ \\
\hline Before 3 PM & $6.96(4.15-11.7)$ & $6.14(2.9-12.81)$ \\
\hline Before 4 PM & $8.22(4.78-14.15)$ & $9.01(4.41-21.43)$ \\
\hline Before 5 PM & $9.36(5.37-16.33)$ & $12.44(5.24-27.36)$ \\
\hline Before 6 PM & $10.26(5.88-17.95)$ & $15.65(7.34-37.64)$ \\
\hline Before 7 PM & $10.79(6.23-18.75)$ & $17.40(7.7-37.94)$ \\
\hline Before 8 PM & $10.88(6.38-18.6)$ & $16.57(7.92-38.37)$ \\
\hline Before 9 PM & $10.47(6.28-17.52)$ & $13.11(6.05-27.03)$ \\
\hline Before $10 \mathrm{PM}$ & $9.60(5.91-15.68)$ & $8.35(4.28-18.27)$ \\
\hline Before $11 \mathrm{PM}$ & $8.36(5.47-13.96)$ & $4.16(2.02-7.98)$ \\
\hline
\end{tabular}

${ }^{a}$ Mean moderate-to-vigorous physical activity (MVPA) for nonsports participators $=24.45 \mathrm{~min}$.

${ }^{b}$ Mean MVPA for sports participators $=40.81$ minutes.

${ }^{\mathrm{c}} \mathrm{N} / \mathrm{A}$ : not applicable.

${ }^{\mathrm{d}}$ Significant differences in odds ratios between groups based on nonoverlapping CIs. 
Figure 4. Involvement in organized sports differences in odds ratios of obtaining average moderate-to-vigorous physical activity before each hour of day.

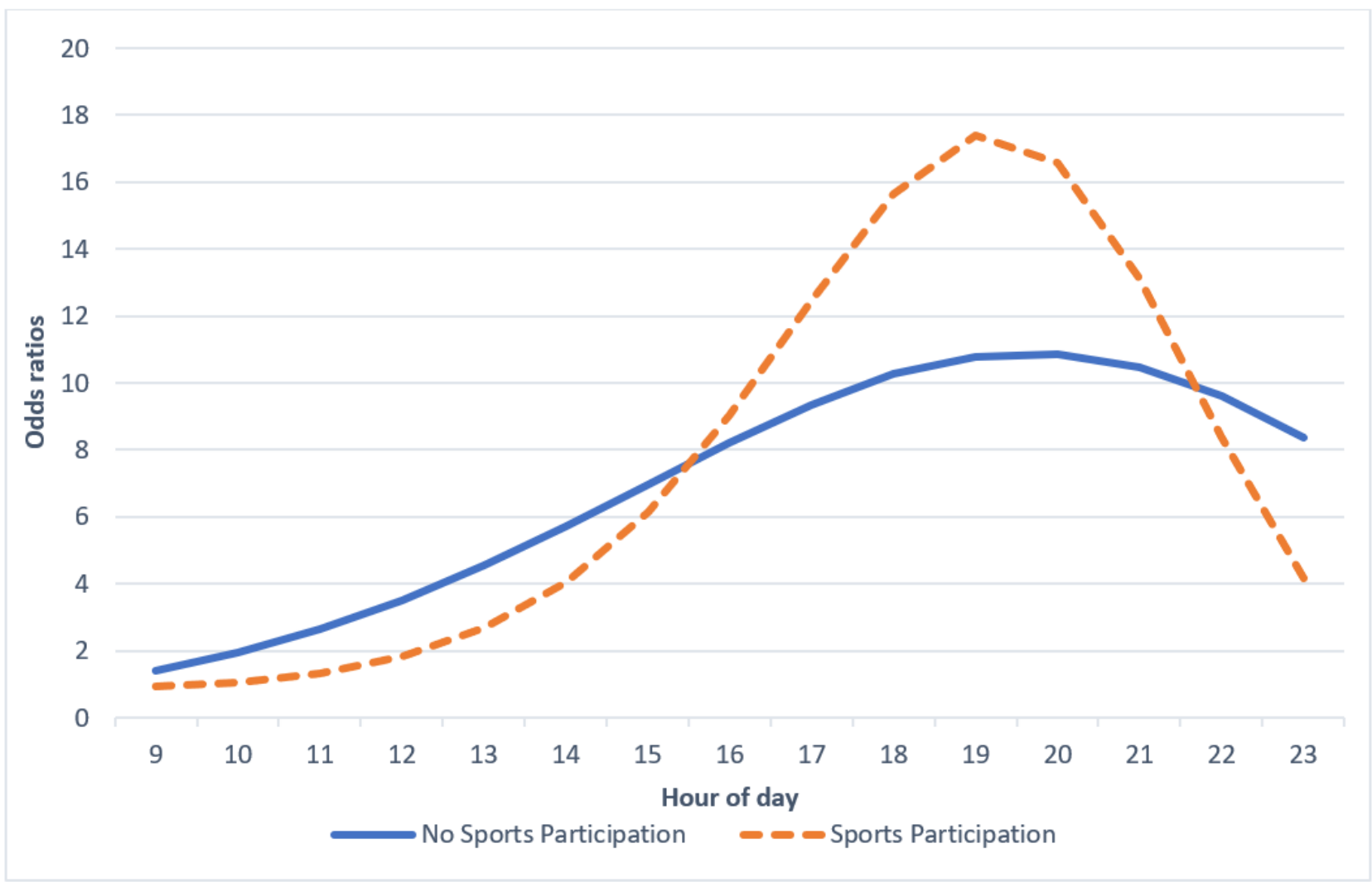


Table 5. Moderating effect of school day on odds ratio estimates of time of average moderate-to-vigorous physical activity accumulation.

\begin{tabular}{|c|c|c|}
\hline \multirow[t]{2}{*}{ Hour } & \multicolumn{2}{|l|}{ Odds ratio estimates $(95 \% \mathrm{CI})$} \\
\hline & Nonschool day ${ }^{\mathrm{a}}$ (1036 days) & School day ${ }^{\mathrm{b}}$ (862 days) \\
\hline Before 8 AM (reference) & $N / A^{c}$ & N/A \\
\hline Before 9 AM & $1.55(1.63-1.77)^{\mathrm{d}}$ & $0.99(0.87-1.12)$ \\
\hline Before 10 AM & $2.34(1.82-3)^{\mathrm{d}}$ & $1.1(0.86-1.4)$ \\
\hline Before $11 \mathrm{AM}$ & $3.41(2.4-4.83)^{\mathrm{d}}$ & $1.34(0.95-1.88)$ \\
\hline Before noon & $4.79(3.08-7.39)^{\mathrm{d}}$ & $1.76(1.15-2.68)$ \\
\hline Before 1 PM & $6.48(3.87-10.73)$ & $2.43(1.47-3.95)$ \\
\hline Before 2 PM & $8.43(4.73-14.75)$ & $3.44(1.97-5.89)$ \\
\hline Before 3 PM & $10.50(5.63-19.17)$ & $4.88(2.67-8.67)$ \\
\hline Before 4 PM & $12.52(6.5-23.48)$ & $6.77(3.59-12.31)$ \\
\hline Before 5 PM & $14.25(7.25-27.09)$ & $9.00(4.67-16.51)$ \\
\hline Before 6 PM & $15.44(7.8-29.37)$ & $11.16(5.75-20.43)$ \\
\hline Before 7 PM & $15.91(8.06-29.9)$ & $12.65(6.53-22.82)$ \\
\hline Before 8 PM & $15.54(7.99-28.56)$ & $12.78(6.66-22.52)$ \\
\hline Before 9 PM & $14.37(7.54-25.59)$ & $11.26(5.95-19.25)$ \\
\hline Before $10 \mathrm{PM}$ & $12.54(6.76-21.54)$ & $8.44(5.53-13.99)$ \\
\hline Before 11 PM & $10.32(5.7-17.08)$ & $5.27(2.85-8.5)$ \\
\hline
\end{tabular}

${ }^{\mathrm{a}}$ Mean moderate-to-vigorous physical activity (MVPA) on nonschool days=28.49 min.

${ }^{b}$ Mean MVPA on school days $=33.82 \mathrm{~min}$.

${ }^{\mathrm{c}} \mathrm{N} / \mathrm{A}$ : not applicable.

${ }^{\mathrm{d}}$ Significant differences in ORs between groups based on nonoverlapping CIs. 
Figure 5. School day differences in odds ratios of obtaining average moderate-to-vigorous physical activity before each hour of day.

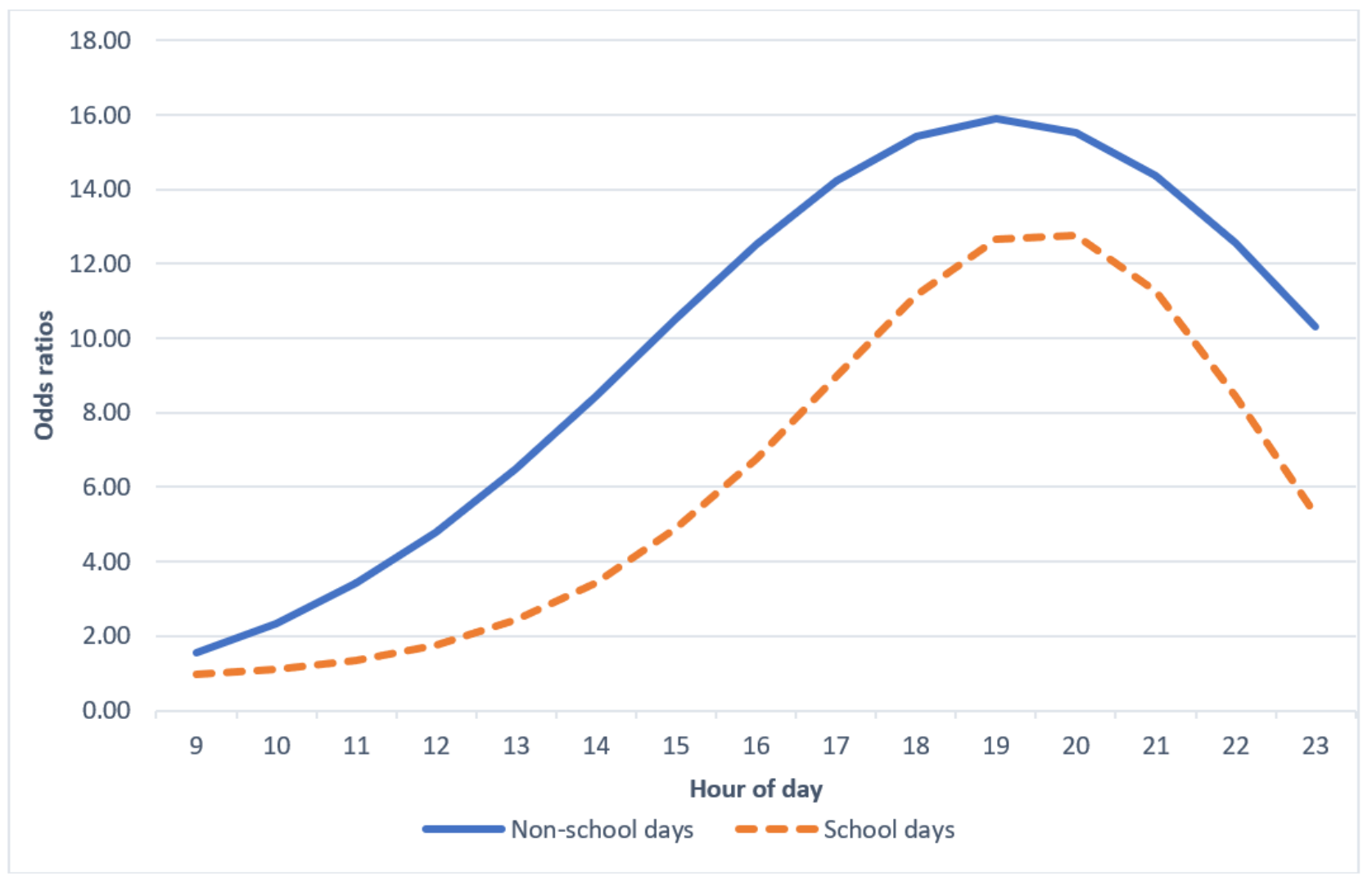

\section{$\operatorname{Aim} 3$}

On average, hazard probabilities indicated that adolescents were most likely to instantaneously meet their average MVPA between 5 PM and 8 PM (Table 6). OR estimates and hazard probabilities indicate slightly different times owing to their mathematical computation. The most likely times offered by the OR estimates and hazard probabilities generally overlap and are conceptually congruent. Survival probabilities demonstrate that after 8 PM, adolescents had a 73\% chance of not meeting their own MVPA average (Table 6 and Figure 6). The sharp decline $(-12 \%)$ in survival probabilities between 5 PM and 8 PM indicates that adolescents' risk of not meeting their average MVPA drastically reduced during this time compared with the windows of time before and after this period. Intervention decision points should therefore be prioritized during this period (5 PM to $8 \mathrm{PM}$ ).

On the basis of the criteria set in place for generating decision points for moderators, sex was the only moderator that upheld both criteria. Although men were significantly more likely to meet their average MVPA during the $8 \mathrm{AM}$ to noon time, there are essentially no differences in the hazard and survival probabilities of MVPA accumulation during this window. Nonetheless, sex differences in the OR estimates at these times indicate that the timing of activity may differ across sexes. Overall, male adolescents might benefit from additional digital support for exercise during the morning hours compared with females. 
Table 6. Hazard and survival probabilities of time of average moderate-to-vigorous physical activity accumulation.

\begin{tabular}{lll}
\hline Hour & Hazard probability & Survival probability \\
\hline Before 8 AM & 0.00 & 1.00 \\
Before 9 AM & 0.01 & 0.00 \\
Before 10 AM & 0.01 & 0.98 \\
Before 11 AM & 0.01 & 0.97 \\
Before noon & 0.01 & 0.96 \\
Before 1 PM & 0.02 & 0.94 \\
Before 2 PM & 0.03 & 0.91 \\
Before 3 PM & 0.03 & 0.88 \\
Before 4 PM & 0.04 & 0.85 \\
Before 5 PM & 0.05 & 0.81 \\
Before 6 PM & 0.05 & 0.77 \\
Before 7 PM & 0.05 & 0.73 \\
Before 8 PM & 0.04 & 0.70 \\
Before 9 PM & 0.04 & 0.68 \\
Before 10 PM & 0.03 & 0.66 \\
Before 11 PM & 0.00 & \\
\hline
\end{tabular}

Figure 6. Survival probabilities of obtaining average moderate-to-vigorous physical activity before each hour of day.

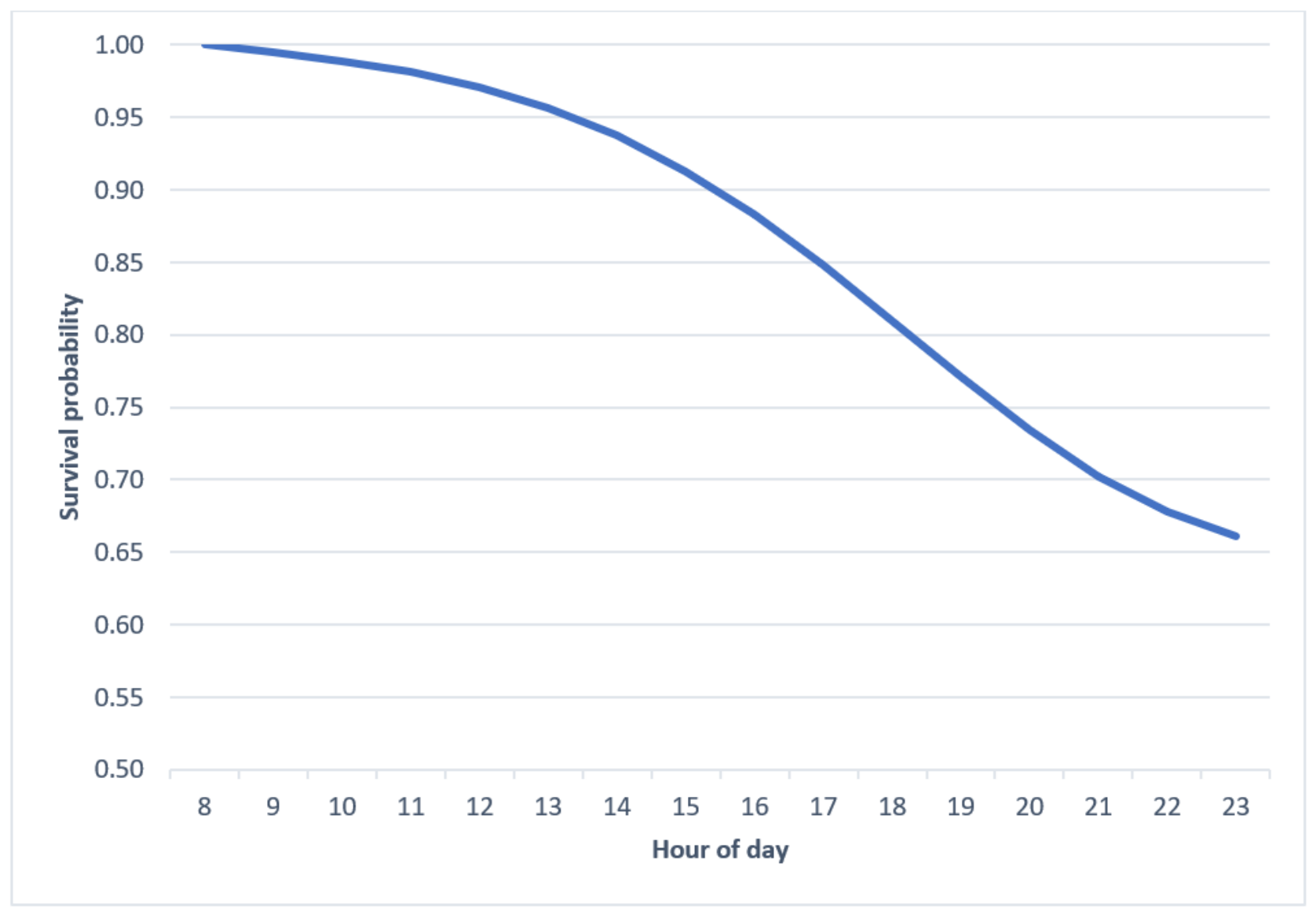




\section{Discussion}

\section{Principal Findings}

The purpose of this study was to explore the timing of exercise for adolescents, identify correlates of physical activity that moderate the timing of exercise, and generate decision points for digital physical activity interventions. No other studies were found that explored the time of day when adolescents meet their typical levels of MVPA or the time of day when adolescents generally exercise. The pattern of ORs, hazard probabilities, and survival probabilities indicating typical MVPA attainment in the late afternoon and early evening (5 PM to 8 PM) coincides with adolescents' daily schedule. Generally, adolescents' ability to exercise is constrained by their school attendance, designating early-to-mid afternoon as the earliest convenience for adolescents to meaningfully accrue MVPA [46]. Furthermore, the decline in ORs, as well as hazard probabilities after 8 PM can be explained by adolescents' needs to attend to other important routines, such as eating dinner, completing homework, and preparing for the next day [47]. Therefore, adolescents may be less likely to engage with digital health intervention options outside of this window of time, and digital support to encourage exercise during these times could be wasteful. This persistent inopportune support is likely to lead to intervention failure and decreased user engagement, a continual challenge in the digital health literature [14-16,48]. These findings suggest that just-in-time support during this window could be most helpful for adolescents and lead to positive engagement with digital support for exercise.

These findings show that males have significantly higher odds of obtaining their average MVPA in the morning compared with females. These findings highlight that daily exercise patterns may vary by sex. Furthermore, these results suggest that male adolescents may benefit from exercise prompts in the morning and in the afternoon, whereas female adolescents might only benefit from exercise prompts later in the day. In other words, although it could be wasteful to prompt female adolescents to exercise in the morning, supplementary digital support for exercise in the morning (eg, $8 \mathrm{AM}$ to noon) could be helpful for male adolescents. Although sending digital support for exercise in the morning to males could be conceived as wasteful, given that they are in school, research demonstrates that male adolescents obtain more exercise than female adolescents in school, including when leisurely on school grounds and also when at recess and gym class [49]. Therefore, digital support for male teenagers during this time may prove beneficial.

There were no significant differences in the timing of the attainment of typical MVPA across groups of different weight statuses. Although previous research has indicated that youths with overweight and obesity exercise less, this study did not find substantial differences in MVPA levels across weight statuses (Table 3) [25,28]. The absence of MVPA differences across groups of varying weight statues probably contributed to the lack of timing differences across these groups. In this case, BMI may not affect the actual timing of exercise. Surprisingly, nonsports participants had significantly higher odds of obtaining their typical MVPA in the morning compared with sports participators. Consistent with previous research, sports participants in this study displayed a higher mean MVPA (Table 4) [50]. Therefore, it should take longer for sports participants to accumulate their typical levels of MVPA compared with nonsports participants. This relationship between higher MVPA averages and later timing of typical MVPA attainment may explain why these results contradict the hypothesis. In addition, this finding reflects adolescents' typical sports practice and game schedule such that sports participants may be engaging in MVPA later in the day after school practices or evening games.

There were higher odds of MVPA attainment in the morning on nonschool days than on school days, which may be indicative of the lack of constraints that prevent exercise on school days, especially considering that there were similar levels of mean MVPA across school vs nonschool days (Table 5). In other words, there may be more opportunities for adolescents to exercise in the morning on nonschool days, which might modify the timing of support on those days [30].

On the basis of this study, decision points for JITAIs promoting exercise could occur between the 5 PM and 8 PM time frame and between $8 \mathrm{AM}$ and noon for male teenagers, as indicated by ORs, hazard probabilities, and survival probabilities. This period appears to overlap with adolescent exercise patterns and could serve as an optimal starting place for novice exercisers to accrue MVPA. In addition, on days when youths have met their typical MVPA by this window, this period could serve as an opportunity to make exercise gains. It should be added that survival probabilities indicated that youths are still $73 \%$ unlikely to obtain their typical MVPA after 8 PM. There were more days when adolescents did not meet their average than the days they did. This finding indicates that encouraging adolescents to consistently meet their own MVPA average would constitute a meaningful shift in MVPA attainment and a consequent increase in their typical MVPA levels, which could arrest the decline in MVPA observed during adolescence.

\section{Limitations and Future Directions}

To determine when users engaged in exercise, this study investigated the time of day when adolescents met their mean MVPA. Some users probably do not accrue MVPA in extensive, continuous bouts of time; rather, they likely obtain MVPA over intermittent spans of time throughout the day [46]. For instance, a person may gain some MVPA walking to school in the morning, in gym class, and after school in sports practice. Therefore, users may engage in exercise multiple times throughout the day, and this study's conceptualization of physical activity timing does not capture this pattern. Furthermore, the timing of obtaining a typical MVPA is likely to be earlier for individuals who typically accrue little-to-no MVPA compared with those who typically accrue more MVPA. Given that these results are averages across individuals, it is also important to acknowledge the potential inability to generalize this average physical activity timing profile to other samples and populations. In addition, interventions based on these results need to consider individual variability in physical activity timing based on their unique activity patterns. In other 
words, the decision points to improve exercise might differ between sedentary adolescents and active adolescents. For example, because sedentary adolescents might need more prompts to exercise or might have already obtained their typical levels of MVPA earlier in the day, decision points for a sedentary adolescent could occur more frequently, such as after prolonged bouts of sedentary time, whereas a more active adolescent might benefit from decision points at the times when they are usually physically active.

This study included participants recruited from different seasons of the year (eg, winter and summer), and although season may affect the timing of MVPA, by distributing data collection throughout the year, our findings are more generalizable than if they were taken from a single season. In this study, weekend days during the school year and weekdays during the summer were both classified as nonschool days, given that the lack of school during both these types of days could similarly affect the timing of activity. However, this study did not evaluate the seasonal effect of physical activity timing, which is a limitation of the study. In addition, work hours or other contexts that would constrain an adolescent's ability to engage in MVPA were not assessed in the study. Future research should consider how these contexts would suppress one's ability to exercise and ultimately affect their decision points.

Each of the moderators in aim 2 was analyzed independently of the others. In reality, these variables are not mutually exclusive and interact, such that there could have been unlimited interactions between these variables that moderated the most likely time of exercise. Future research should consider a more nuanced examination of how these moderators in tandem influence the timing of exercise to better optimize decision points for physical activity JITAIs across multiple contexts. Another limitation of the study is that it did not seek to determine which moderator of timing would be the most useful for adjusting decision points. Therefore, future research should investigate the experimental effects of tailoring decision points via different situational and contextual factors on improvements in physical activity.

Furthermore, it is possible that other variables might moderate the timing of exercise, including one's built environment characteristics (eg, neighborhood walkability and access to recreational activities; [51-53]). For example, youths who actively transport (eg, biking and walking) themselves to and from school might engage in more MVPA during these windows. Moreover, the moderators evaluated in this study are mostly participant-level factors (except for the day of week). It is likely that time-varying or within-person factors also moderate typical MVPA attainment. Ultimately, this study demonstrates that it is possible to investigate how important correlates of physical activity moderate the timing of exercise. Future research should explore how additional variables, including time-varying factors, influence the timing of exercise. Such an approach would help identify dynamic receptive states to develop a truly just-in-time intervention that adapts to an individual's changing internal and contextual state.

A key element of JITAI research and implementation is the need to identify states of vulnerability or states of receptivity for users [16,54]. A state of vulnerability is a dynamic state in which an individual is likely to exhibit health-compromising behaviors, whereas a state of receptivity is a dynamic state in which an individual is open to performing health-promoting behaviors, is likely to be responsive to health promoting cues, or is likely to be engaged with intervention options [16,54]. Decision points should, therefore, overlap with these states to deliver intervention options at critical windows of opportunity $[16,54]$. As stated previously, the empirically identified times found in this study represent periods when these participants were more likely to have already accumulated their typical MVPA but do not necessarily reflect periods when users are receptive to digital support. In other words, this study determined the time of day when adolescents are typically available for obtaining physical activity. However, this 5 PM to $8 \mathrm{PM}$ availability might not completely overlap when adolescents are most responsive to digital health-promoting cues or likely to be engaged with digital intervention options. Therefore, additional research is required to determine when adolescents may benefit the most from digital support, such as investigating times of day when adolescents are most likely to exercise and concurrently engage with a digital health intervention.

Developing decision points for JITAIs by investigating the timing of exercise is a direct answer to calls in the research literature to model and incorporate microtemporal dynamics of health determinants or the study of behavioral phenomena in small timescales, within health behavior science [16,32,55]. Expansion of health behavior research to the microtimescale may elucidate the temporal specificity of health behaviors such as physical activity [16,55]. In addition, because the microtemporal study of physical activity can be continuously monitored and passively detected, JITAIs can therefore optimize and adapt interventions for each individual user more readily than in-person and static digital interventions. Most importantly, with these temporally dense data sets, researchers can statistically uncover the unique temporal patterns for each participant, given the immense quantity of observations $[53,56]$. It is conceivable that activity patterns may be highly idiosyncratic depending on the temporal, contextual, and psychosocial processes involved. However, with these idiographic data, automated JITAIs can be tailored to match the temporal specificity of each individual user's microtemporal physical activity patterns. Future research exploring the timing of exercise and decision points generally should, therefore, consider employing idiographic methods, such as precision medicine approaches, to enhance decision points for each user [57,58].

Ultimately, the notion that improved timing of support for digital physical activity interventions will lead to improvements in physical activity requires experimental testing. This study demonstrates that decision points can be empirically defined and that the timing of exercise may differ among groups of people but did not evaluate the impact of tailoring these decision points on adolescent physical activity. To address this gap, it should be empirically tested if sending digital support at empirically identified moments leads to more exercise compared with digital support at interventionist-defined or user-defined 
times. Major areas for future research include investigating the impact of sending digital support at the empirically identified window (5 PM to $8 \mathrm{PM}$ ) on physical activity, evaluating adolescent receptivity to digital support during this time as well as generating and tailoring idiographic decision points based on an individual's unique physical activity patterns.

\section{Acknowledgments}

This project was supported by a targeted research grant from the Society of Pediatric Psychology awarded to the second author. The paper processing charges related to the publication of this study were supported by the University of Kansas (KU) One University Open Access Author Fund sponsored jointly by the KU Provost, KU Vice Chancellor for Research and Graduate Studies, and KU Medical Center Vice Chancellor for Research and managed jointly by the Libraries at the Medical Center and KU, Lawrence.

\section{Conflicts of Interest}

None declared.

\section{References}

1. Katzmarzyk P, Denstel K, Beals K, Bolling C, Wright C, Crouter SE, et al. Results from the United States of America's 2016 report card on physical activity for children and youth. J Phys Act Health 2016 Nov;13(11 Suppl 2):S307-S313 [FREE Full text] [doi: 10.1123/jpah.2016-0321] [Medline: 27848726]

2. Lee I, Shiroma EJ, Lobelo F, Puska P, Blair SN, Katzmarzyk PT, Lancet Physical Activity Series Working Group. Effect of physical inactivity on major non-communicable diseases worldwide: an analysis of burden of disease and life expectancy. Lancet 2012 Jul 21;380(9838):219-229 [FREE Full text] [doi: 10.1016/S0140-6736(12)61031-9] [Medline: 22818936]

3. Danaei G, Ding EL, Mozaffarian D, Taylor B, Rehm J, Murray CJ, et al. The preventable causes of death in the United States: comparative risk assessment of dietary, lifestyle, and metabolic risk factors. PLoS Med 2009 Apr 28;6(4):e1000058 [FREE Full text] [doi: 10.1371/journal.pmed.1000058] [Medline: 19399161]

4. Hootman JM. 2008 Physical activity guidelines for Americans: an opportunity for athletic trainers. J Athl Train 2009;44(1):5-6 [FREE Full text] [doi: 10.4085/1062-6050-44.1.5] [Medline: 19180212]

5. Nader PR, Bradley TH, Houts RM, McRitchie SL, O'Brien M. Moderate-to-vigorous physical activity from ages 9 to 15 years. J Am Med Assoc 2008 Jul 16;300(3):295-305. [doi: 10.1001/jama.300.3.295] [Medline: 18632544]

6. Telama R. Tracking of physical activity from childhood to adulthood: a review. Obes Facts 2009;2(3):187-195 [FREE Full text] [doi: 10.1159/000222244] [Medline: 20054224]

7. Pedisic Z, Dumuid D, Olds T. Integrating sleep, sedentary behaviour, and physical activity research in the emerging field of time-use epidemiology: definitions, concepts, statistical methods, theoretical framework, and future directions. Kinesiology 2017;49:252-269 [FREE Full text]

8. Tremblay MS, Carson V, Chaput J. Introduction to the Canadian 24-hour movement guidelines for children and youth: an integration of physical activity, sedentary behaviour, and sleep. Appl Physiol Nutr Metab 2016 Jun;41(6 Suppl 3):iii-iiv. [doi: 10.1139/apnm-2016-0203] [Medline: 27306430]

9. Krietsch KN, Armstrong B, McCrae CS, Janicke DM. Temporal associations between sleep and physical activity among overweight/obese youth. J Pediatr Psychol 2016 Jul;41(6):680-691 [FREE Full text] [doi: 10.1093/jpepsy/jsv167] [Medline: 26801238]

10. Grgic J, Dumuid D, Bengoechea EG, Shrestha N, Bauman A, Olds T, et al. Health outcomes associated with reallocations of time between sleep, sedentary behaviour, and physical activity: a systematic scoping review of isotemporal substitution studies. Int J Behav Nutr Phys Act 2018 Jul 13;15(1):69 [FREE Full text] [doi: 10.1186/s12966-018-0691-3] [Medline: 30001713]

11. Pagoto S, Bennett GG. How behavioral science can advance digital health. Transl Behav Med 2013 Sep;3(3):271-276 [FREE Full text] [doi: 10.1007/s13142-013-0234-z] [Medline: 24073178]

12. Cushing C, Fedele D, Riley W. Introduction to the coordinated special issue on ehealth $/ \mathrm{mhealth}$ in pediatric psychology. J Pediatr Psychol 2019 Apr 1;44(3):259-262 [FREE Full text] [doi: 10.1093/jpepsy/jsz010] [Medline: $\underline{30806658}$ ]

13. Fedele DA, Cushing CC, Fritz A, Amaro CM, Ortega A. Mobile health interventions for improving health outcomes in youth: a meta-analysis. JAMA Pediatr 2017 May 1;171(5):461-469 [FREE Full text] [doi: 10.1001/jamapediatrics.2017.0042] [Medline: 28319239]

14. Yardley L, Spring BJ, Riper H, Morrison LG, Crane DH, Curtis K, et al. Understanding and promoting effective engagement with digital behavior change interventions. Am J Prev Med 2016 Nov;51(5):833-842. [doi: 10.1016/j.amepre.2016.06.015] [Medline: 27745683]

15. Psihogios AM, Li Y, Butler E, Hamilton J, Daniel LC, Barakat LP, et al. Text message responsivity in a 2-way short message service pilot intervention with adolescent and young adult survivors of cancer. JMIR Mhealth Uhealth 2019 Apr 18;7(4):e12547 [FREE Full text] [doi: 10.2196/12547] [Medline: 30998225] 
16. Nahum-Shani I, Smith SN, Spring BJ, Collins LM, Witkiewitz K, Tewari A, et al. Just-in-time adaptive interventions (JITAIs) in mobile health: key components and design principles for ongoing health behavior support. Ann Behav Med 2018 May 18;52(6):446-462 [FREE Full text] [doi: 10.1007/s12160-016-9830-8] [Medline: 27663578]

17. Riley WT, Rivera DE, Atienza AA, Nilsen W, Allison SM, Mermelstein R. Health behavior models in the age of mobile interventions: are our theories up to the task? Transl Behav Med 2011 Mar;1(1):53-71 [FREE Full text] [doi:

10.1007/s13142-011-0021-7] [Medline: 21796270]

18. Hardeman W, Houghton J, Lane K, Jones A, Naughton F. A systematic review of just-in-time adaptive interventions (JITAIs) to promote physical activity. Int J Behav Nutr Phys Act 2019 Apr 3;16(1):31 [FREE Full text] [doi: 10.1186/s12966-019-0792-7] [Medline: 30943983]

19. Bond DS, Thomas JG, Raynor HA, Moon J, Sieling J, Trautvetter J, et al. B-MOBILE-a smartphone-based intervention to reduce sedentary time in overweight/obese individuals: a within-subjects experimental trial. PLoS One 2014;9(6):e100821 [FREE Full text] [doi: 10.1371/journal.pone.0100821] [Medline: 24964010]

20. Pellegrini CA, Hoffman SA, Daly ER, Murillo M, Iakovlev G, Spring B. Acceptability of smartphone technology to interrupt sedentary time in adults with diabetes. Transl Behav Med 2015 Sep;5(3):307-314 [FREE Full text] [doi: 10.1007/s13142-015-0314-3] [Medline: 26327936]

21. van Dantzig S, Geleijnse G, van Halteren AT. Toward a persuasive mobile application to reduce sedentary behavior. Pers Ubiquit Comput 2012 Jul 12;17(6):1237-1246. [doi: 10.1007/s00779-012-0588-0]

22. Finkelstein J, Bedra M, Li X, Wood J, Ouyang P. Mobile app to reduce inactivity in sedentary overweight women. Stud Health Technol Inform 2015;216:89-92. [Medline: 26262016]

23. Hermens H, op den Akker H, Tabak M, Wijsman J, Vollenbroek M. Personalized coaching systems to support healthy behavior in people with chronic conditions. J Electromyogr Kinesiol 2014 Dec;24(6):815-826. [doi:

10.1016/j.jelekin.2014.10.003] [Medline: 25455254]

24. van Dantzig S, Bulut M, Krans M, van der Lans A, de Ruyte B. Enhancing Physical Activity Through Context-Aware Coaching. In: Proceedings of the 12th EAI International Conference on Pervasive Computing Technologies for Healthcare. 2018 Presented at: PervasiveHealth'18; May 21-24, 2018; New York, USA p. 187-190. [doi: 10.1145/3240925.3240928]

25. Trost S, Kerr L, Ward D, Pate R. Physical activity and determinants of physical activity in obese and non-obese children. Int J Obes Relat Metab Disord 2001 Jun;25(6):822-829. [doi: 10.1038/sj.ijo.0801621] [Medline: 11439296]

26. Trost SG, Pate RR, Sallis JF, Freedson PS, Taylor WC, Dowda M, et al. Age and gender differences in objectively measured physical activity in youth. Med Sci Sports Exerc 2002 Feb;34(2):350-355. [doi: 10.1097/00005768-200202000-00025] [Medline: 11828247]

27. van der Horst K, Paw MJ, Twisk JW, van Mechelen W. A brief review on correlates of physical activity and sedentariness in youth. Med Sci Sports Exerc 2007 Aug;39(8):1241-1250. [doi: 10.1249/mss.0b013e318059bf35] [Medline: 17762356]

28. Elgar F, Roberts C, Moore L, Tudor-Smith C. Sedentary behaviour, physical activity and weight problems in adolescents in Wales. Public Health 2005 Jun;119(6):518-524. [doi: 10.1016/j.puhe.2004.10.011] [Medline: 15826893]

29. Wickel EE, Eisenmann JC. Contribution of youth sport to total daily physical activity among 6- to 12-yr-old boys. Med Sci Sports Exerc 2007 Sep;39(9):1493-1500. [doi: 10.1249/mss.0b013e318093f56a] [Medline: 17805079]

30. Moore J, Beets M, Morris S, Kolbe M. Day of the week is associated with meeting physical activity recommendations and engaging in excessive sedentary time in youth. J Phys Act Health 2014 Jul;11(5):971-976. [doi: 10.1123/jpah.2012-0190] [Medline: 23676713]

31. Centers for Disease Control and Prevention. 2011. National Health and Nutrition Examination Survey (NHANES): Physical Activity Monitor (PAM) Procedures Manual URL: http://www.cdc.gov/nchs/data/nhanes/nhanes 11 12/

Physical Activity Monitor Manual.pdf [accessed 2020-04-07]

32. Cushing CC, Mitchell TB, Bejarano CM, Walters RW, Crick CJ, Noser AE. Bidirectional associations between psychological states and physical activity in adolescents: a mHealth pilot study. J Pediatr Psychol 2017 Jun 1;42(5):559-568. [doi: 10.1093/jpepsy/jsw099] [Medline: 28131985]

33. Sadeh A, Sharkey M, Carskadon M. Activity-based sleep-wake identification: an empirical test of methodological issues. Sleep 1994 Apr;17(3):201-207. [doi: 10.1093/sleep/17.3.201] [Medline: 7939118]

34. Troiano RP, Berrigan D, Dodd KW, Mâsse LC, Tilert T, McDowell M. Physical activity in the United States measured by accelerometer. Med Sci Sports Exerc 2008 Jan;40(1):181-188. [doi: 10.1249/mss.0b013e31815a51b3] [Medline: 18091006]

35. Chandler JL, Brazendale K, Beets MW, Mealing BA. Classification of physical activity intensities using a wrist-worn accelerometer in 8-12-year-old children. Pediatr Obes 2016 Apr;11(2):120-127. [doi: 10.1111/ijpo.12033] [Medline: 25893950]

36. Dössegger A, Ruch N, Jimmy G, Braun-Fahrländer C, Mäder U, Hänggi J, et al. Reactivity to accelerometer measurement of children and adolescents. Med Sci Sports Exerc 2014 Jun;46(6):1140-1146 [FREE Full text] [doi: 10.1249/MSS.0000000000000215] [Medline: 24219978]

37. Kuczmarski R, Ogden C, Guo S, Grummer-Strawn LM, Flegal KM, Mei Z, et al. 2000 CDC Growth Charts for the United States: methods and development. Vital Health Stat 112002 May(246):1-190 [FREE Full text] [Medline: 12043359]

38. Centers for Disease Control and Prevention. 2016. A SAS Program for the 2000 CDC Growth Charts (Ages 0 to <20 Years) URL: https://www.cdc.gov/nccdphp/dnpao/growthcharts/resources/sas.htm [accessed 2019-06-26] 
39. Dowda M, Ainsworth BE, Addy CL, Saunders R, Riner W. Environmental influences, physical activity, and weight status in 8- to 16-year-olds. Arch Pediatr Adolesc Med 2001 Jun;155(6):711-717. [doi: 10.1001/archpedi.155.6.711] [Medline: $\underline{11386963]}$

40. Lajunen H, Keski-Rahkonen A, Pulkkinen L, Rose RJ, Rissanen A, Kaprio J. Leisure activity patterns and their associations with overweight: a prospective study among adolescents. J Adolesc 2009 Oct;32(5):1089-1103 [FREE Full text] [doi: 10.1016/j.adolescence.2009.03.006] [Medline: 19345989]

41. Walters S, Barr-Anderson DJ, Wall M, Neumark-Sztainer D. Does participation in organized sports predict future physical activity for adolescents from diverse economic backgrounds? J Adolesc Health 2009 Mar;44(3):268-274. [doi: 10.1016/j.jadohealth.2008.08.011] [Medline: 19237113]

42. von Hippel PT, Powell B, Downey DB, Rowland NJ. The effect of school on overweight in childhood: gain in body mass index during the school year and during summer vacation. Am J Public Health 2007 Apr;97(4):696-702. [doi:

10.2105/AJPH.2005.080754] [Medline: 17329660]

43. Hox J, Moerbeek M, van de Schoot R. Multilevel Analysis: Techniques and Applications. Second Edition. New York, USA: Routledge; 2010.

44. Greenland S, Senn SJ, Rothman KJ, Carlin JB, Poole C, Goodman SN, et al. Statistical tests, P values, confidence intervals, and power: a guide to misinterpretations. Eur J Epidemiol 2016 Apr;31(4):337-350 [FREE Full text] [doi:

10.1007/s 10654-016-0149-3] [Medline: 27209009]

45. Singer JD, Willett JB. Applied Longitudinal Data Analysis: Modeling Change and Event Occurrence. New York, USA: Oxford University Press; 2003.

46. Brooke HL, Atkin AJ, Corder K, Brage S, van Sluijs EM. Frequency and duration of physical activity bouts in school-aged children: a comparison within and between days. Prev Med Rep 2016 Dec;4:585-590 [FREE Full text] [doi:

10.1016/j.pmedr.2016.10.007] [Medline: 27843758]

47. Gyurcsik NC, Spink KS, Bray SR, Chad K, Kwan M. An ecologically based examination of barriers to physical activity in students from grade seven through first-year university. J Adolesc Health 2006 Jun;38(6):704-711. [doi: 10.1016/j.jadohealth.2005.06.007] [Medline: 16730599]

48. Scherer EA, Ben-Zeev D, Li Z, Kane JM. Analyzing mhealth engagement: joint models for intensively collected user engagement data. JMIR Mhealth Uhealth 2017 Jan 12;5(1):e1 [FREE Full text] [doi: 10.2196/mhealth.6474] [Medline: 28082257]

49. Klinker CD, Schipperijn J, Christian H, Kerr J, Ersbøll AK, Troelsen J. Using accelerometers and global positioning system devices to assess gender and age differences in children's school, transport, leisure and home based physical activity. Int $\mathbf{J}$ Behav Nutr Phys Act 2014 Jan 24;11:8 [FREE Full text] [doi: 10.1186/1479-5868-11-8] [Medline: 24457029]

50. Sallis JF, Prochaska JJ, Taylor WC. A review of correlates of physical activity of children and adolescents. Med Sci Sports Exerc 2000 May;32(5):963-975. [doi: 10.1097/00005768-200005000-00014] [Medline: 10795788]

51. Ding D, Sallis JF, Kerr J, Lee S, Rosenberg DE. Neighborhood environment and physical activity among youth a review. Am J Prev Med 2011 Oct;41(4):442-455. [doi: 10.1016/j.amepre.2011.06.036] [Medline: 21961474]

52. Sallis JF, Conway TL, Cain KL, Carlson JA, Frank LD, Kerr J, et al. Neighborhood built environment and socioeconomic status in relation to physical activity, sedentary behavior, and weight status of adolescents. Prev Med 2018 May;110:47-54 [FREE Full text] [doi: 10.1016/j.ypmed.2018.02.009] [Medline: 29432790]

53. Cushing C, Monzon A, Ortega A, Bejarano C, Carlson J. Commentary: identifying opportunities for pediatric ehealth and mhealth studies: physical activity as a case example. J Pediatr Psychol 2019 Apr 1;44(3):269-274. [doi: 10.1093/jpepsy/jsz005] [Medline: $\underline{30835782]}$

54. Nahum-Shani I, Hekler EB, Spruijt-Metz D. Building health behavior models to guide the development of just-in-time adaptive interventions: a pragmatic framework. Health Psychol 2015 Dec;34S:1209-1219 [FREE Full text] [doi: 10.1037/hea0000306] [Medline: 26651462]

55. Dunton GF. Sustaining health-protective behaviors such as physical activity and healthy eating. J Am Med Assoc 2018 Aug 21;320(7):639-640. [doi: 10.1001/jama.2018.6621] [Medline: 29852046]

56. Hamaker E. Why researchers should think 'within-person': a paradigmatic rationale. In: Mehl MR, Conner TS, editors. Handbook of Research Methods for Studying Daily Life. New York, USA: The Guilford Press; 2012:43-61.

57. Collins FS, Varmus H. A new initiative on precision medicine. N Engl J Med 2015 Feb 26;372(9):793-795 [FREE Full text] [doi: 10.1056/NEJMp1500523] [Medline: 25635347]

58. Cnossen R, Corporation I, Heetderks W, Nibib P, Kumar S. National Institutes of Health. 2013. Precision Medicine Meeting (Feb 11-12). White Paper: Data Collection and Mobile Technologies URL: https://www.nih.gov/sites/default/files/ research-training/initiatives/pmi/data-collection-mobile-technologies.pdf [accessed 2020-04-20]

\section{Abbreviations}

CDC: Center for Disease Control and Prevention

JITAI: just-in-time adaptive intervention

KU: University of Kansas 
MVPA: moderate-to-vigorous physical activity

OR: odds ratio

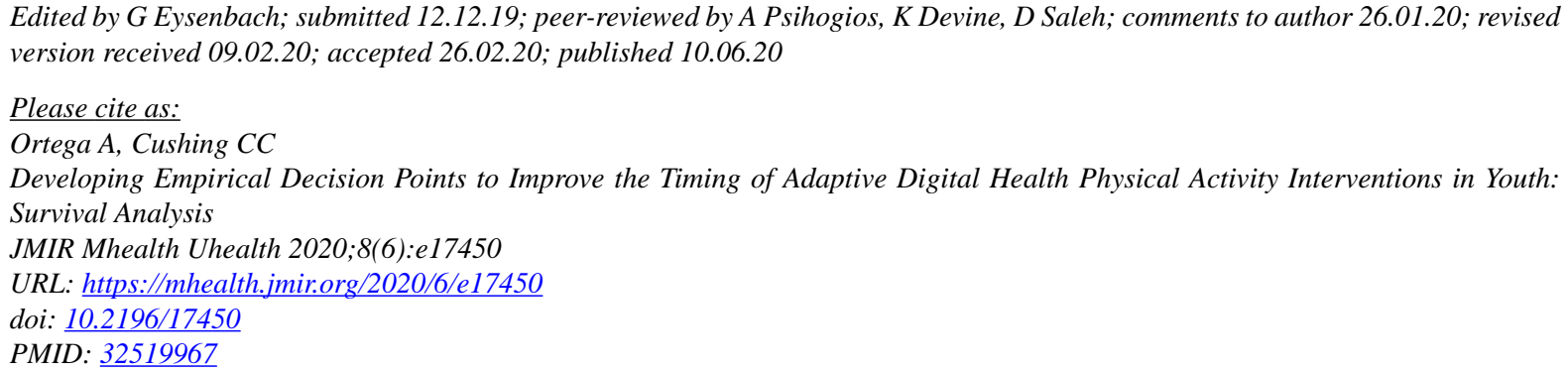

(CAdrian Ortega, Christopher C Cushing. Originally published in JMIR mHealth and uHealth (http://mhealth.jmir.org), 10.06.2020. This is an open-access article distributed under the terms of the Creative Commons Attribution License (https://creativecommons.org/licenses/by/4.0/), which permits unrestricted use, distribution, and reproduction in any medium, provided the original work, first published in JMIR mHealth and uHealth, is properly cited. The complete bibliographic information, a link to the original publication on http://mhealth.jmir.org/, as well as this copyright and license information must be included. 